\title{
Efficacy of Cholesterol Levels and Ratios in Predicting Future Coronary Heart Disease in a Chinese Population
}

\author{
Tzung-Dau Wang, MD, Wen-Jone Chen, MD, Kuo-Liong Chien, MD, \\ Sophia Seh-Yi Su, PhD, Hsiu-Ching Hsu, PhD, Ming-Fong Chen, MD, \\ Chiau-Suong Liau, MD, and Yuan-Teh Lee, MD
}

In this study, we assessed the efficacy of various lipid and lipoprotein measurements at baseline for predicting the risk for coronary heart disease (CHD) and determined the associated risk of CHD in subgroups stratified by different lipid and lipoprotein screening strategies to evaluate the adequacy of current total and low-density lipoprotein (LDL) cholesterol-based approaches in lipid management. We analyzed data from the Chin-Shan Community Cardiovascular Cohort study, a Chinese population-based prospective cohort study that began in 1990. During an 8-year follow-up period, 213 of 3,159 participants $(6.7 \%$ ) without CHD (aged $\geq 35$ years) developed CHD. The total cholesterol/high-density lipoprotein (HDL) cholesterol ratio was the most powerful lipoprotein predictor of future CHD (hazard ratio 1.21 for a 1.0 increment in ratio; $p<0.001)$. Subjects with "highrisk" LDL cholesterol levels (>160 mg/dl) and low total cholesterol/HDL cholesterol ratios ( $\leq 5$ ) had an incidence of CHD similar to those with low levels of both LDL cholesterol ( $\leq 130 \mathrm{mg} / \mathrm{dl}$ ) and total cholesterol/HDL cholesterol ratios $(4.9 \%$ vs $4.6 \%)$. In contrast, subjects with "low-risk" LDL cholesterol levels ( $\leq 130 \mathrm{mg} / \mathrm{dl}$ ) and high total cholesterol/HDL cholesterol ratios (>5) had a 2.5fold higher incidence of CHD than those with similar LDL cholesterol levels but low total cholesterol/HDL cholesterol ratios ( $p<0.001$ ). Compared with using an LDL cholesterol level of $130 \mathrm{mg} / \mathrm{dl}$ as the cut-off point, using a total cholesterol/HDL cholesterol ratio of 5 was associated with superior specificity $(73 \%$ vs $59 \%, p<0.001)$ and accuracy $(72 \%$ vs $58 \%, p<0.001)$, and similar sensitivity ( $50 \%$ vs $53 \%$ ). Our data indicate that current guidelines for lipid management may misclassify subjects with high levels of HDL and LDL cholesterol as well as those with low levels of HDL and LDL cholesterol. Using the ratio of total to HDL cholesterol as the initial screening tool can obviate this discrepancy. ( 2001 by Excerpta Medica, Inc.

(Am J Cardiol 2001;88:737-743)
$\mathbf{A}$ lthough elevated levels of low-density lipoprotein (LDL) cholesterol and low levels of highdensity lipoprotein (HDL) cholesterol have both been designated as risk factors for coronary heart disease (CHD),${ }^{1-4}$ several important issues in clinical management of dyslipidemic patients remain to be solved. For example, there is a continuing debate as to whether subjects with high levels of HDL and LDL cholesterol have an increased risk for CHD. The same problem confronts clinicians in managing subjects with low levels of HDL and LDL cholesterol. Recent studies have shown that the total cholesterol/HDL cholesterol ratio is a powerful lipoprotein predictor for the development of CHD. ${ }^{5,6}$ Although this concept has not been integrated into current clinical guidelines, ${ }^{3,4}$ it has been suggested that using the total cholesterol/HDL cholesterol ratio as a stratifying vari-

\footnotetext{
From the Departments of Internal Medicine (Cardiology) and Emergency Medicine, National Taiwan University Hospital, Taipei, Taiwan, Republic of China. This study was supported in part by grants from the Department of Health (DOH82-TD-068) and National Science Council (NSC83-04 1 2-B002-064), Taipei, Taiwan, Republic of China. Manuscript received March 16, 2001; revised manuscript received and accepted May 17, 2001.

Address for reprints: Yuan-Teh Lee, MD, Department of Internal Medicine (Cardiology), National Taiwan University Hospital, 7 Chung-Shan South Road, Taipei, 100, Taiwan, Republic of China. E-mail: ytlee@ha.mc.ntu.edu.tw.
}

able may help clinicians to better clarify the risk status of subjects with high levels of HDL and LDL cholesterol as well as those with low levels of HDL and LDL cholesterol. In this study, by using the 8-year follow-up data of participants without CHD in a wellcharacterized Chinese population-based prospective cohort study - the Chin-Shan Community Cardiovascular Cohort (CCCC) study-we first assessed the efficacy of various lipid and lipoprotein measurements at baseline for predicting the risk for future coronary events. Then, we determined the associated risk of CHD in subgroups stratified by different lipid and lipoprotein screening strategies to evaluate the adequacy of current total and LDL cholesterol-based approaches in lipid management.

\section{METHODS}

Subjects: The present study was based on the original cohort of the CCCC study, which began in 1990 to 1991 as a Chinese population-based prospective cardiovascular study. The study population included 1,703 men and 1,899 women aged $\geq 35$ years, with a participation rate of $82.8 \%$. All participants were recruited from the 1990 residential registration files of the Chin-Shan community in northern Taiwan. Details of the study design have been previously described. ${ }^{7}$ This study was approved by the Ethics Committee of 
the National Taiwan University Hospital. All subjects gave their informed consent before examination.

At enrollment, participants who had a history of myocardial infarction, major $\mathrm{Q} / \mathrm{QS}$ waves on electrocardiograms at rest, angina pectoris, stroke, or intermittent claudication were excluded from the analyses. The World Health Organization criteria for verified definite or possible myocardial infarction were used to define previous myocardial infarction. ${ }^{8}$ A history of stroke was defined on the basis of a history of hemiparesis or hemiplegia, and was confirmed by 1 neurologist. Information regarding angina pectoris and intermittent claudication was established from questionnaires. Of the 3,602 participants, 286 were eliminated due to a history of myocardial infarction or unstable angina $(\mathrm{n}=52)$, previous stroke $(\mathrm{n}=80)$, unavailable or inadequate blood sampling at enrollment $(\mathrm{n}=104)$, and use of lipid-lowering medications $(\mathrm{n}=50)$. Subjects with triglyceride levels $>400$ $\mathrm{mg} / \mathrm{dl}(\mathrm{n}=55)$, a level at which the indirect LDL cholesterol calculation becomes unreliable, ${ }^{9}$ were also excluded. An additional 102 subjects were eliminated because of significant systemic illnesses, such as renal insufficiency (serum creatinine levels more than twice the upper limit of normal) $(n=2)$, liver impairment (alanine transaminase levels more than twice the upper limit of normal) $(\mathrm{n}=91)$, acute or chronic infections $(n=4)$, or neoplastic disease $(n=5)$. Finally, 3,159 participants were included in the present analyses.

Subjects were considered hypertensive if they were receiving drug treatment for hypertension or if they had a systolic pressure $\geq 140 \mathrm{~mm} \mathrm{Hg}$ or a diastolic pressure $\geq 90 \mathrm{~mm} \mathrm{Hg}$. Diabetes mellitus was diagnosed if the subject had a fasting glucose level $\geq 140$ $\mathrm{mg} / \mathrm{dl}$ or was taking insulin or an oral hypoglycemic agent. Smoking history was considered in the data analyses by use of a dichotomous classification: current nonsmokers (those who never smoked or who had ceased tobacco use within 3 months) versus current smokers.

Venous blood samples were obtained after a 12hour overnight fast for measurements of clinical chemistry profiles. Standard enzymatic methods were used to determine serum cholesterol and triglycerides (methods 14354 and 14366, respectively; Merck, Darmstadt, Germany). ${ }^{10}$ HDL cholesterol was measured in the supernatant after precipitation with magnesium chloride-phosphotungstate reagents (method 14993; Merck). LDL cholesterol was determined indirectly according to the formula of Friedewald et al. ${ }^{9}$ Concentrations of apolipoprotein A1 and B were measured by turbidmetric immunoassay using commercial kits (Sigma, St. Louis, Missouri). The coefficients of variation for all clinical chemistry parameters were $<5 \%$. The current investigation used baseline data collected between 1990 and 1991.

Prospective follow-up: The follow-up period extended from the 1990 to 1991 examination period for each subject until July 1, 1998. Information on hospital admissions and death certificate diagnoses, which were further validated by reviewing related medical records, ${ }^{7}$ within the follow-up period were obtained. The underlying cause of death was coded by use of the ninth revision of the International Classification of Diseases (ICD). ICD codes 410 through 414 formed the CHD death category. An incident CHD event was defined as the first nonfatal myocardial infarction, silent myocardial infarction identified by the occurrence of new diagnostic $Q$ waves on routine biennial electrocardiography, angina corroborated by objective evidence of ischemia, coronary revascularization, or angiographic evidence of stenosis $>50 \%$ of the luminal diameter in $\geq 1$ major epicardial coronary arteries, or CHD death without a preceding nonfatal coronary event.

Statistical analysis: Data analyses were performed with the SAS statistical software package, version 6.11 (SAS Institute, Cary, North Carolina). The results for continuous variables are given as means \pm SD or percentages. The differences among the groups were assessed by chi-square analysis (for categorical data) or Student's 2-tailed $t$ test (for continuous data) for independent samples, when appropriate. Multivariate Cox regression models that additionally controlled for body mass index, smoking, history of diabetes, and hypertension were then used to investigate the association between the incidence of CHD and various lipoprotein and apolipoprotein levels treated as continuous variables. Univariate and multivariate Cox regression models were used to evaluate the relative risks of CHD and all-cause mortality between dyslipidemic categories. The cut-off points of LDL cholesterol and the total cholesterol/HDL cholesterol ratio were chosen by using the receiver-operating characteristic curve analysis to identify values that were associated with the smallest sum of $(1-\text { sensitivity })^{2}$ and $(1-\text { specificity })^{2}$. The accuracy of different lipid and lipoprotein screening strategies was defined as the number of subjects with true positive or true negative results divided by the number of all subjects in the present study. All p values were 2-sided.

\section{RESULTS}

Baseline characteristics: During the 8-year follow-up period, 213 of the 3,159 participants $(6.7 \%)$ had a first CHD event, either fatal or nonfatal. As expected, subjects with a first coronary event were older and had a higher body mass index, higher blood pressure, and a higher prevalence of diabetes (Table 1). They also had significantly higher levels of total cholesterol, LDL cholesterol, triglycerides, and apolipoprotein $\mathrm{B}$, higher ratios of total to HDL cholesterol and LDL to HDL cholesterol, and significantly lower levels of HDL cholesterol and apolipoprotein A1 at baseline. There was no significant difference in the sexual distribution between subjects with and without CHD events. Serum levels of total cholesterol in the present cohort were approximately $20 \mathrm{mg} / \mathrm{dl}$ lower than those in the third National Health and Nutrition Examination Survey in the United States (data collected from 1988 to 1991). ${ }^{11,12}$

Lipoprotein predictors of coronary heart disease: Table 2 displays the results of multivariate Cox propor- 
TABLE 1 Baseline Characteristics According to Outcome

\begin{tabular}{|c|c|c|c|}
\hline \multirow[b]{2}{*}{ Characteristic } & \multicolumn{2}{|c|}{ Coronary Event } & \multirow[b]{2}{*}{$\mathrm{p}$ Value } \\
\hline & $\begin{array}{c}+ \\
(n=213)\end{array}$ & $\begin{aligned} & 0 \\
&(n=2,946)\end{aligned}$ & \\
\hline Age (yrs) & $61.0 \pm 11.1$ & $53.6 \pm 12.1$ & $<0.001$ \\
\hline Men & $51.2 \%$ & $45.7 \%$ & 0.12 \\
\hline Body mass index $\left(\mathrm{kg} / \mathrm{m}^{2}\right)$ & $24.0 \pm 3.5$ & $23.4 \pm 3.4$ & 0.011 \\
\hline Systemic hypertension & $46.0 \%$ & $25.3 \%$ & $<0.001$ \\
\hline Diabetes mellitus & $10.3 \%$ & $7.0 \%$ & 0.053 \\
\hline Current smoker & $34.3 \%$ & $30.2 \%$ & 0.21 \\
\hline \multicolumn{4}{|l|}{ Blood pressure $(\mathrm{mm} \mathrm{Hg})$} \\
\hline Systolic & $134 \pm 24$ & $124 \pm 20$ & $<0.001$ \\
\hline Diastolic & $80 \pm 12$ & $77 \pm 11$ & $<0.001$ \\
\hline Total cholesterol $(\mathrm{mg} / \mathrm{dl})$ & $205 \pm 43$ & $197 \pm 44$ & 0.011 \\
\hline HDL cholesterol (mg/dl) & $44 \pm 12$ & $48 \pm 12$ & $<0.001$ \\
\hline LDL cholesterol (mg/dl) & $134 \pm 39$ & $125 \pm 41$ & 0.001 \\
\hline Triglycerides (mg/dl) & $131 \pm 78$ & $114 \pm 67$ & 0.002 \\
\hline $\begin{array}{l}\text { Total cholesterol/HDL } \\
\text { cholesterol ratio }\end{array}$ & $5.01 \pm 1.61$ & $4.30 \pm 1.39$ & $<0.001$ \\
\hline $\begin{array}{l}\text { LDL cholesterol/HDL } \\
\text { cholesterol ratio }\end{array}$ & $3.32 \pm 1.32$ & $2.77 \pm 1.15$ & $<0.001$ \\
\hline Apolipoprotein Al (mg/dl) & $121 \pm 23$ & $128 \pm 25$ & $<0.001$ \\
\hline Apolipoprotein B (mg/dl) & $101 \pm 32$ & $93 \pm 30$ & $<0.001$ \\
\hline & & & \\
\hline
\end{tabular}

\begin{tabular}{|c|c|c|c|c|}
\hline Variable & Difference & $\begin{array}{l}\text { Wald Chi- } \\
\text { Square }\end{array}$ & $\begin{array}{l}\text { Hazard Ratio } \\
(95 \% \mathrm{Cl})\end{array}$ & $p$ Value \\
\hline Total cholesterol & $10 \mathrm{mg} / \mathrm{dl}$ & 0.68 & 1.01 (0.98-1.04) & 0.41 \\
\hline HDL cholesterol & $1 \mathrm{mg} / \mathrm{dl}$ & 16.01 & 0.97 (0.96-0.99) & $<0.001$ \\
\hline LDL cholesterol & $10 \mathrm{mg} / \mathrm{dl}$ & 2.16 & 1.03 (0.99-1.06) & 0.14 \\
\hline Triglycerides & $10 \mathrm{mg} / \mathrm{dl}$ & 2.66 & 1.02 (1.00-1.04) & 0.10 \\
\hline $\begin{array}{l}\text { Total cholesterol/HDL } \\
\text { cholesterol ratio }\end{array}$ & 1 & 19.50 & $1.21(1.11-1.32)$ & $<0.001$ \\
\hline $\begin{array}{l}\text { LDL cholesterol/HDL } \\
\text { cholesterol ratio }\end{array}$ & 1 & 17.63 & $1.24(1.12-1.38)$ & $<0.001$ \\
\hline Apolipoprotein Al & $10 \mathrm{mg} / \mathrm{dl}$ & 0.01 & 1.00 (0.98-1.02) & 0.91 \\
\hline Apolipoprotein B & 10 mg/dl & 2.32 & $1.02(0.99-1.05)$ & 0.13 \\
\hline \multicolumn{5}{|c|}{$\begin{array}{l}\text { In each model, the covariates included are age, sex, body mass index, smoking, hypertension, and } \\
\text { diabetes. } \\
\mathrm{Cl}=\text { confidence interval. }\end{array}$} \\
\hline
\end{tabular}

tional-hazard models assessing the independent predictive value of various lipoprotein and apolipoprotein levels. HDL cholesterol and the ratios of total to HDL cholesterol and LDL to HDL cholesterol remained significant predictors of CHD after adjustment for age, sex, body mass index, smoking, hypertension, and diabetes. The ratio of total to HDL cholesterol was a more powerful predictor than the level of either cholesterol alone and the ratio of LDL to HDL cholesterol. Further adjustment for triglycerides did not affect the relation between the ratio of total to HDL cholesterol and the risk of CHD. Nonsignificant trends were observed for levels of LDL cholesterol, triglycerides, and apolipoprotein B. These estimates remained virtually unchanged in sex-specific analyses.

Risk of CHD in subgroups stratified by different lipid screening strategies: To assess the adequacy of current total and LDL cholesterol-based guidelines for lipid management, we divided subjects into 4 groups on the basis of serum LDL cholesterol levels and the ratios of total to HDL cholesterol at baseline. The cut-off point of LDL cholesterol levels was $130 \mathrm{mg} / \mathrm{dl}$ by using the receiver-operating characteristic curve analysis. This level is the same as that recommended by current guidelines. $^{3,4}$ The cut-off point of total cholesterol/ HDL cholesterol ratios was 5 (cut-off point of the highest quartile). In sex-specific analyses, the cut-off points of both LDL cholesterol and the ratio of total to HDL cholesterol remained unchanged. Clinical characteristics of the 4 groups are listed in Table 3 . The clustering of major risk factors in subjects with a high total cholesterol/HDL cholesterol ratio suggests that they may be insulin resistant. ${ }^{13}$ In contrast, subjects with high LDL cholesterol levels $(>130 \mathrm{mg} / \mathrm{dl})$ and low total cholesterol/HDL cholesterol ratios $(\leq 5)$ had a similar risk factor profile to that in those with low levels of both LDL cholesterol and total cholesterol/ HDL cholesterol.

Table 4 shows the 8-year incidence of CHD and all-cause mortality according to dyslipidemic categories classified by 2 different criteria. In the upper half of the table, subjects were classified according to the same criteria used in Table 3. In the lower half of the table, subjects were classified on the basis of LDL cholesterol and HDL cholesterol levels (cut-off points, 130 and $35 \mathrm{mg} / \mathrm{dl}$, respectively), as suggested by current guidelines. The incidence of CHD was significantly higher in subjects with a high ratio of total to HDL cholesterol and an LDL cholesterol level $\leq 130$ or $>130$ $\mathrm{mg} / \mathrm{dl}(12.2 \%$ and $11.7 \%$, respectively) than in subjects with low levels of both LDL cholesterol and total cholesterol/HDL cholesterol (4.6\%). Of interest is that subjects with an LDL cholesterol level $>130 \mathrm{mg} / \mathrm{dl}$ and a low total cholesterol/HDL cholesterol ratio were not associated with an increased incidence of CHD (5.1\%). Furthermore, in subjects with an LDL cholesterol level $>160 \mathrm{mg} / \mathrm{dl}$, only if their total cholesterol/ HDL cholesterol ratio was $\leq 5$, was the incidence of CHD still as low as that in subjects with low levels of both LDL cholesterol and total cholesterol/HDL cholesterol. In contrast, despite having an LDL cholesterol level $<100 \mathrm{mg} / \mathrm{dl}$, subjects with a high total to HDL cholesterol ratio $(>5)$ were at a significantly higher risk for CHD (data not shown). The risk for all-cause mortality had a similar pattern as the incidence of CHD across dyslipidemic categories, although it was not statistically significant.

Kaplan-Meier estimates of the probability of eventfree survival demonstrated that subjects with a total cholesterol/HDL cholesterol ratio $>5$ had worse prognosis than those with a total cholesterol/HDL cholesterol ratio $\leq 5$, regardless of their LDL cholesterol 
TABLE 3 Risk Factors for Coronary Heart Disease at Baseline Among Subjects Categorized by Serum Low-Density Lipoprotein (LDL) Cholesterol Levels and Total Cholesterol/High-Density Lipoprotein (HDL) Cholesterol Ratios

\begin{tabular}{|c|c|c|c|c|}
\hline \multirow[b]{2}{*}{ Variable } & \multicolumn{2}{|c|}{ LDL Cholesterol $\leq 130 \mathrm{mg} / \mathrm{dl}$} & \multicolumn{2}{|c|}{ LDL Cholesterol > 130 mg/dl } \\
\hline & $\begin{array}{l}\text { Total Cholesterol/HDL } \\
\text { Cholesterol } \leq 5 \\
(\mathrm{n}=1,610)\end{array}$ & $\begin{array}{l}\text { Total Cholesterol/HDL } \\
\text { Cholesterol }>5 \\
(\mathrm{n}=221)\end{array}$ & $\begin{array}{l}\text { Total Cholesterol/HDL } \\
\text { Cholesterol } \leq 5 \\
(\mathrm{n}=652)\end{array}$ & $\begin{array}{l}\text { Total Cholesterol/HDL } \\
\text { Cholesterol }>5 \\
(\mathrm{n}=676)\end{array}$ \\
\hline Age (yrs) & $52.0 \pm 12.2$ & $55.4 \pm 12.4^{*}$ & $55.4 \pm 11.7^{*}$ & $57.2 \pm 11.6^{*}$ \\
\hline Men & $48.5 \%$ & $59.7 \%^{\dagger}$ & $35.9 \%$ * & $42.9 \%^{\dagger}$ \\
\hline Body mass index $\left(\mathrm{kg} / \mathrm{m}^{2}\right)$ & $22.8 \pm 3.2$ & $25.3 \pm 3.4^{*}$ & $23.0 \pm 3.2$ & $24.6 \pm 3.3^{*}$ \\
\hline Systemic hypertension & $20.6 \%$ & $38.0 \%$ * & $25.5 \%^{\ddagger}$ & $39.2 \%$ * \\
\hline Diabetes mellitus & $5.3 \%$ & $14.5 \%$ * & $4.9 \%$ & $12.3 \%$ * \\
\hline Current smoker & $32.6 \%$ & $36.2 \%{ }^{\ddagger}$ & $22.4 \%$ * & $29.6 \%$ \\
\hline \multicolumn{5}{|l|}{ Blood pressure (mm Hg) } \\
\hline Systolic & $122 \pm 19$ & $130 \pm 21 *$ & $125 \pm 21$ * & $131 \pm 21$ * \\
\hline Diastolic & $76 \pm 11$ & $80 \pm 12 *$ & $77 \pm 11$ & $79 \pm 11$ * \\
\hline Total cholesterol (mg/dl) & $167 \pm 24$ & $182 \pm 23^{*}$ & $227 \pm 26^{*}$ & $245 \pm 39^{*}$ \\
\hline HDL cholesterol (mg/dl) & $50 \pm 12$ & $32 \pm 5^{*}$ & $55 \pm 10^{*}$ & $40 \pm 7^{*}$ \\
\hline $\mathrm{LDL}$ cholesterol (mg/dl) & $105 \pm 22$ & $118 \pm 20^{*}$ & $159 \pm 22^{*}$ & $190 \pm 36^{*}$ \\
\hline Triglycerides (mg/dl) & $97 \pm 51$ & $210 \pm 82^{*}$ & $90 \pm 40$ & $153 \pm 74^{*}$ \\
\hline $\begin{array}{l}\text { Total cholesterol/HDL } \\
\text { cholesterol ratio }\end{array}$ & $3.43 \pm 0.72$ & $5.76 \pm 0.78^{*}$ & $4.17 \pm 0.54^{*}$ & $6.26 \pm 1.15^{*}$ \\
\hline $\begin{array}{l}\text { LDL cholesterol/HDL } \\
\text { cholesterol ratio }\end{array}$ & $2.01 \pm 0.59$ & $3.42 \pm 0.55^{*}$ & $2.83 \pm 0.46^{*}$ & $4.46 \pm 0.97^{*}$ \\
\hline Apolipoprotein Al (mg/dl) & $129 \pm 24$ & $108 \pm 21^{*}$ & $139 \pm 24^{*}$ & $120 \pm 21^{*}$ \\
\hline Apolipoprotein B (mg/dl) & $75 \pm 20$ & $101 \pm 23^{*}$ & $94 \pm 23^{*}$ & $120 \pm 28^{*}$ \\
\hline
\end{tabular}

levels (Figure 1). Despite that multiple coronary risk factors were clustered in subjects with high total cholesterol/HDL cholesterol ratios, as shown in Table 3, the incidence of CHD remained significantly higher in both groups with total cholesterol/HDL cholesterol ratios $>5$ after adjustment for age, sex, body mass index, smoking, hypertension, diabetes, and triglycerides.

Efficacy of different lipid screening strategies: To evaluate the adequacy of current guidelines for lipid management in the present cohort, we assessed the sensitivity, specificity, and accuracy of 4 different screening strategies (total cholesterol/HDL cholesterol ratio $>5$, LDL cholesterol $>130 \mathrm{mg} / \mathrm{dl}$, LDL cholesterol $>130 \mathrm{mg} / \mathrm{dl}$ or HDL cholesterol $<35 \mathrm{mg} / \mathrm{dl}$, and total cholesterol/HDL cholesterol $>5$ or HDL cholesterol $<35 \mathrm{mg} / \mathrm{dl}$ ) in helping to identify subjects at risk of developing CHD (Table 5). The results showed that using the total cholesterol/HDL cholesterol ratio alone as the stratifying variable was associated with the best specificity and accuracy compared with the other screening strategies. Use of LDL cholesterol alone, as recommended by current guidelines, was associated with similar sensitivity but significantly lower specificity and accuracy than the ratio alone. Use of HDL cholesterol and LDL cholesterol in combination was associated with significantly higher sensitivity but lower specificity and accuracy than the ratio alone. Compared with using the total cholesterol/HDL cholesterol ratio alone as the stratifying variable, use of HDL cholesterol and the total cholesterol/HDL cholesterol ratio in combination was not associated with better discriminating ability.

\section{DISCUSSION}

The major findings in the present study are: (1) the total cholesterol/HDL cholesterol ratio was the most powerful lipoprotein discriminator of future coronary events, irrespective of age, sex, and various cardiovascular risk factors; (2) subjects with "high-risk" LDL cholesterol levels $(>160 \mathrm{mg} / \mathrm{dl})$ but low total cholesterol/HDL cholesterol ratios $(\leq 5)$ had a low incidence of CHD, which was similar to that in subjects with low levels of both LDL cholesterol $(\leq 130$ $\mathrm{mg} / \mathrm{dl}$, the clinically desirable range) and total cholesterol/HDL cholesterol ratios; (3) subjects with "lowrisk" LDL cholesterol levels $(\leq 130 \mathrm{mg} / \mathrm{dl})$ and high total cholesterol/HDL cholesterol ratios $(>5)$ had a significantly higher incidence of CHD than those with similar LDL cholesterol levels but low total cholesterol/HDL cholesterol ratios; and (4) compared with using the LDL cholesterol level of $130 \mathrm{mg} / \mathrm{dl}$ as the cut-off point, using the total cholesterol/HDL cholesterol ratio of 5 was associated with significantly higher specificity and accuracy and similar sensitivity.

Risk of CHD and serum levels of total and LDL cholesterol: It is noteworthy that only nonsignificant trends toward an increased risk for CHD were observed for levels of total and LDL cholesterol in this Chinese population-based study. However, for several reasons, power to detect this association in the present Chinese cohort might be low. First, because the association between total and LDL cholesterol and CHD risks are weaker among older individuals and the mean age of the present cohort is slightly older than that reported in Western studies, ${ }^{14,15}$ this may thus weaken the predictive power of total and LDL cholesterol. Second, because subjects with high levels of 
TABLE 4 Incidence of Coronary Heart Disease Events and All-Cause Mortality During the Eight-Year Follow-Up Period According to Different Categories of Dyslipidemia

\begin{tabular}{|c|c|c|c|c|c|c|c|}
\hline \multirow[b]{2}{*}{ Event } & \multicolumn{3}{|c|}{$\mathrm{LDL}$ Cholesterol $\leq 130 \mathrm{mg} / \mathrm{dl}$} & \multicolumn{4}{|c|}{ LDL Cholesterol >130 mg/dl } \\
\hline & $\begin{array}{c}\text { Total } \\
\text { Cholesterol/HDL } \\
\text { Cholesterol } \leq 5 \\
(\mathrm{n}=1,610)\end{array}$ & $\begin{array}{c}\text { Total } \\
\text { Cholesterol/HDL } \\
\text { Cholesterol }>5 \\
(\mathrm{n}=221)\end{array}$ & $\mathrm{p}$ Value & $\begin{array}{c}\text { Total } \\
\text { Cholesterol/HDL } \\
\text { Cholesterol } \leq 5 \\
(\mathrm{n}=652)\end{array}$ & $p$ Value & $\begin{array}{c}\text { Total } \\
\text { Cholesterol/HDL } \\
\text { Cholesterol }>5 \\
(\mathrm{n}=676)\end{array}$ & $\mathrm{p}$ Value \\
\hline $\begin{array}{l}\text { Fatal or nonfatal CHD } \\
\text { Incidence during follow-up } \\
\text { Events } / 100 \text { person-yrs }\end{array}$ & $\begin{array}{l}4.60 \% \\
0.61\end{array}$ & $\begin{array}{c}12.22 \% \\
1.67\end{array}$ & $<0.001$ & $\begin{array}{l}5.06 \% \\
0.66\end{array}$ & 0.99 & $\begin{array}{c}11.69 \% \\
1.60\end{array}$ & $<0.001$ \\
\hline $\begin{array}{l}\text { Death from all causes } \\
\text { Incidence during follow-up } \\
\text { Events } / 100 \text { person-yrs }\end{array}$ & $\begin{array}{l}7.52 \% \\
0.99\end{array}$ & $\begin{array}{c}10.41 \% \\
1.42\end{array}$ & 0.82 & $\begin{array}{l}6.75 \% \\
0.89\end{array}$ & 0.14 & $\begin{array}{c}11.69 \% \\
1.60\end{array}$ & 0.22 \\
\hline & $\begin{array}{l}\text { HDL Cholesterol } \\
>35 \mathrm{mg} / \mathrm{dl} \\
(\mathrm{n}=1,587)\end{array}$ & $\begin{array}{l}\text { HDL Cholesterol } \\
\quad \leq 35 \mathrm{mg} / \mathrm{dl} \\
(\mathrm{n}=244)\end{array}$ & $\mathrm{p}$ Value & $\begin{array}{l}\text { HDL Cholesterol } \\
>35 \mathrm{mg} / \mathrm{dl} \\
(\mathrm{n}=1,180)\end{array}$ & p Value & $\begin{array}{l}\text { HDL Cholesterol } \\
\quad \leq 35 \mathrm{mg} / \mathrm{dl} \\
(\mathrm{n}=148)\end{array}$ & $p$ Value \\
\hline $\begin{array}{l}\text { Fatal or nonfatal } \mathrm{CHD} \\
\text { Incidence during follow-up } \\
\text { Events } 100 \text { person-yrs }\end{array}$ & $\begin{array}{l}4.60 \% \\
0.61\end{array}$ & $\begin{array}{l}11.48 \% \\
1.56\end{array}$ & $<0.001$ & $\begin{array}{l}7.12 \% \\
0.95\end{array}$ & 0.059 & $\begin{array}{c}18.92 \% \\
2.63\end{array}$ & $<0.001$ \\
\hline $\begin{array}{l}\text { Death from all causes } \\
\text { Incidence during follow-up } \\
\text { Events } / 100 \text { person-yrs }\end{array}$ & $\begin{array}{l}7.50 \% \\
0.99\end{array}$ & $\begin{array}{l}10.25 \% \\
1.39\end{array}$ & 0.73 & $\begin{array}{l}8.81 \% \\
1.18\end{array}$ & 0.83 & $\begin{array}{l}12.84 \% \\
1.78\end{array}$ & 0.25 \\
\hline
\end{tabular}

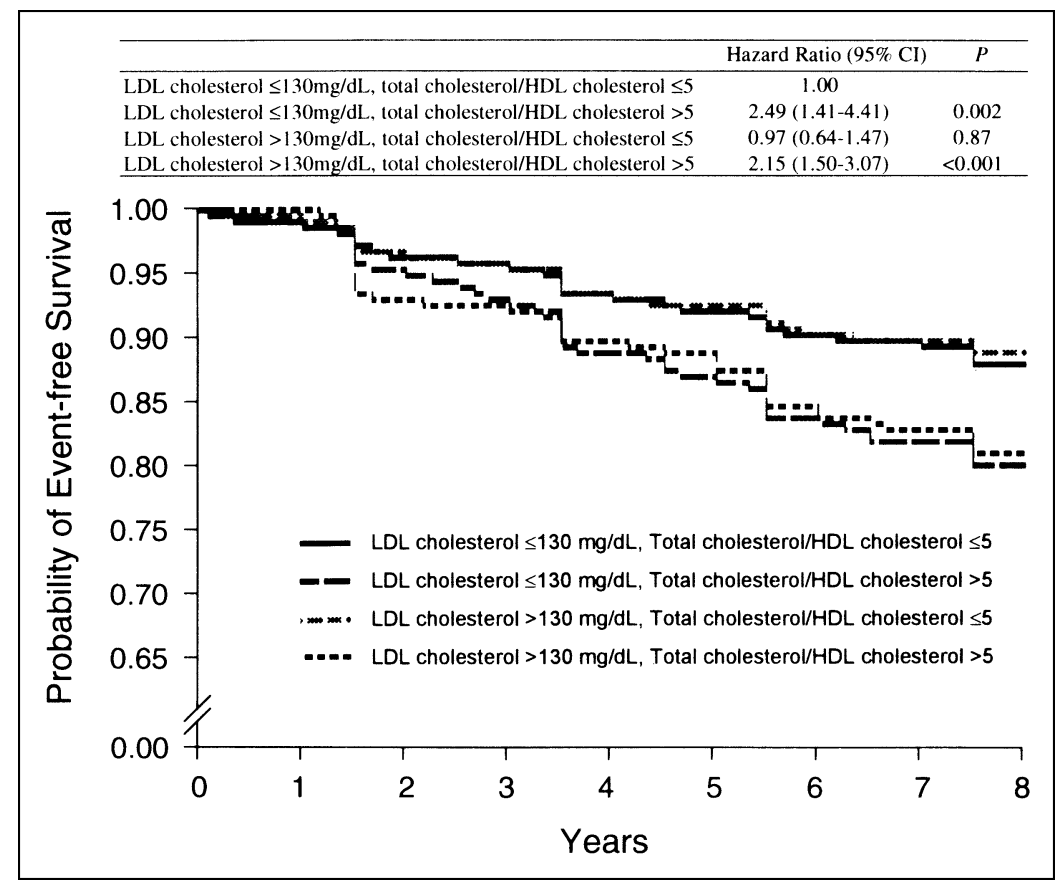

FIGURE 1. Kaplan-Meier survival curves for remaining free of major cardiovascular events during an 8-year follow-up period by serum LDL cholesterol levels and total cholesterol/HDL cholesterol ratios. Hazard ratio and $p$ values were calculated with Cox proportional-hazards models adjusted for age, sex, body mass index, smoking, hypertension, diabetes, and triglycerides. Subjects with an LDL cholesterol level $\leq 130 \mathrm{mg} / \mathrm{dl}$ and a total cholesterol/HDL cholesterol ratio $\leq 5$ served as the reference category. $\mathrm{Cl}=$ confidence intervals.

HDL and LDL cholesterol were actually at low risk for CHD, this may also confound the association between CHD risks and LDL cholesterol. Third, the number of CHD cases was relatively small in this study. Finally, although numerous epidemiologic data demonstrate that the risk of CHD is directly related to the level of total cholesterol or LDL cholesterol, the relation is not linear. The risk of CHD increases slowly as total cholesterol levels increase from 150 to $200 \mathrm{mg} / \mathrm{dl}$, and it increases more rapidly at $\geq 200 \mathrm{mg} / \mathrm{dl}^{1}{ }^{1}$ This may partly explain why only a nonsignificant trend was observed for total cholesterol in the present cohort, of which the mean cholesterol level was $<200 \mathrm{mg} / \mathrm{dl}$. Moreover, it justifies the adoption of LDL cholesterol as the primary target for cholesterol management in guidelines used in Western countries, where cholesterol levels are typically high.

Risk of CHD and the ratio of total to HDL cholesterol: In addition to the present study, there has been a plethora of evidence suggesting that the total cholesterol/HDL cholesterol ratio is a better predictor of the development of CHD across a broad range of total cholesterol levels. ${ }^{5,6,16-19}$ In this study, using total cholesterol/ HDL cholesterol ratio of 5 as the cut-off point was associated with superior specificity and accuracy and similar sensitivity compared with using LDL cholesterol level of $130 \mathrm{mg} / \mathrm{dl}$. Moreover, the annual incidence of CHD in subjects with total cholesterol/HDL cholesterol ratios $>5$ was close to $2 \%$, a proposed 
TABLE 5 Sensitivity, Specificity, and Accuracy of Different Screening Strategies for Identifying Future Coronary Heart Disease

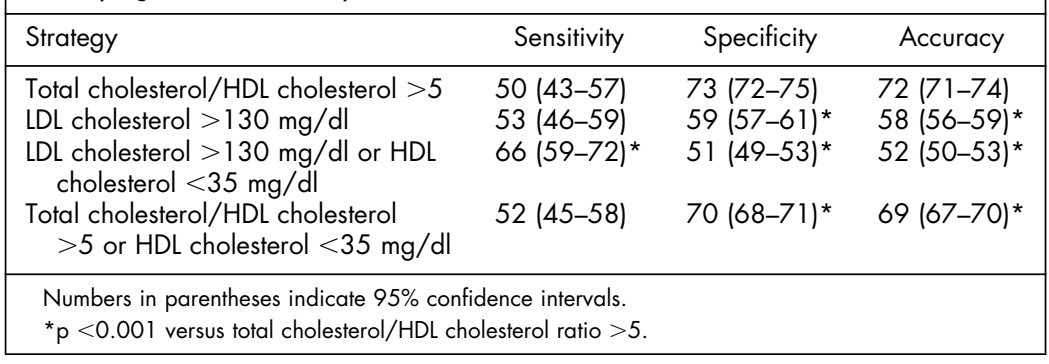

threshold level for the definition of high-risk state and initiation of drug therapy in the setting of primary CHD prevention. ${ }^{20}$ This suggests that the cut-off value of 5 is adequate for stratifying high-risk patients in the Chinese population.

Risk of CHD in subjects with low levels of HDL and LDL cholesterol: In this study, we clearly demonstrated that subjects with low levels of both HDL cholesterol $(\leq 35 \mathrm{mg} / \mathrm{dl})$ and LDL cholesterol $(\leq 130 \mathrm{mg} / \mathrm{dl})$, as well as high total cholesterol/HDL cholesterol ratios, were associated with a significantly higher risk for CHD than those with desirable lipid levels (LDL cholesterol level $\leq 130 \mathrm{mg} / \mathrm{dl}$, HDL cholesterol level $>35 \mathrm{mg} / \mathrm{dl}$ ). Several studies in Western countries have also demonstrated that subjects with desirable total cholesterol and low HDL cholesterol levels were associated with an elevated coronary risk..$^{6,21,22}$ However, in most current guidelines, LDL cholesterol is the principal indicator for risk classification and the primary target for lipid-lowering therapy. HDL cholesterol, as a CHD risk factor, plays only a secondary role in lipid management. Therefore, subjects who have low serum HDL cholesterol levels in isolation are not recommended for treatment. These recommendations obviously underestimate the risk of subjects with isolated low HDL cholesterol levels. Using the ratio of total to HDL cholesterol as the initial screening tool can obviate this discrepancy. Otherwise, HDL cholesterol should be considered as equally important as LDL cholesterol in identifying subjects at high risk for CHD. However, use of HDL and LDL cholesterol in combination as the screening strategy, despite significantly increasing the sensitivity, was still associated with significantly lower specificity and accuracy than use of the ratio alone in the present cohort.

Risk of CHD in subjects with high levels of HDL and LDL cholesterol: Another important message conveyed in this study is that the risk of CHD in subjects with high levels of HDL and LDL cholesterol (with a ratio of total to HDL cholesterol $<5$ ) is actually as low as that in subjects with desirable lipid levels. Glueck et $\mathrm{al}^{23}$ first reported that genetic syndromes of high HDL are associated with longevity and decreased incidence of CHD. It is noteworthy that in the Framingham Study, subjects with high levels of HDL and LDL cholesterol had a lower incidence of CHD than those with low levels of HDL and LDL cholesterol. ${ }^{2}$

Although a high HDL cholesterol level $(\geq 60 \mathrm{mg} /$ dl) has been designated as a negative risk factor, current guidelines recommend that middle-aged subjects with LDL cholesterol levels $\geq 160 \mathrm{mg} / \mathrm{dl}$ should be receiving lipid-lowering therapy regardless of their HDL cholesterol levels. However, our findings indicate that not all hypercholesterolemic subjects are at higher risk for CHD than normocholesterolemic subjects. This observation holds even after controlling for all major coronary risk factors. It is noteworthy that all published primary-prevention or secondary-prevention lipid-intervention trials included patients with an average total cholesterol/HDL cholesterol ratio in excess of $>5$. $^{16-18,22,24,25}$ However, the average level of total cholesterol/HDL cholesterol ratio in Western populations is only $4.5^{12}$ Why there was such a discrepancy is still uncertain. However, the absence of specific clinical trials that document the magnitude of benefit from drug therapy and the low absolute risk in patients without CHD with high levels of HDL and LDL cholesterol allude to the need for more caution when considering aggressive lipid-lowering therapy in this clinical setting.

Study limitations: First, cholesterol levels were measured only once at baseline, so we were unable to account for within-individual variability in the present study. This would likely underestimate the strength of the association of cholesterol levels and CHD. Nevertheless, according to the experience from the Framingham Study, there was an apparent stability of measurements of total and HDL cholesterol taken in the same subjects 8 years apart. ${ }^{15}$ Second, the present analyses focused only on screening for primary prevention and did not evaluate the accuracy of current guidelines for secondary prevention.

1. Stamler J, Wentworth D, Neaton JD, for the MRFIT Research Group. Is relationship between serum cholesterol and risk of premature death from coronary heart disease continuous and graded? Findings in 356,222 primary screenees of the Multiple Risk Factor Intervention Trial (MRFIT). JAMA 1986;256:28232828 .

2. Castelli WP, Garrison RJ, Wilson PWF, Abbott RD, Kalousdian S, Kannel WB. Incidence of coronary heart disease and lipoprotein cholesterol levels. JAMA 1986;256:2835-2838

3. Expert Panel on Detection, Evaluation, and Treatment of High Blood Cholesterol in Adults. Summary of the second report of the National Cholesterol Education Program (NCEP) Expert Panel on Detection, Evaluation, and Treatment of High Blood Cholesterol in Adults. JAMA 1993;269:3015-3023

4. Wood D, DeBacker G, Faergeman O, Graham I, Mancia G, Pyorala K. Prevention of coronary heart disease in clinical practice. Recommendations of the Second Joint Task Force of European and other Societies on Coronary Prevention. Eur Heart J 1998;19:1434-1503

5. Kinosian B, Glick H, Garland G. Cholesterol and coronary heart disease: predicting risks by levels and ratios. Ann Intern Med 1994;121:641-647.

6. Stampfer MJ, Sacks FM, Salvini S, Willett WC, Henneken CH. A prospective study of cholesterol, apolipoproteins, and the risk of myocardial infarction. N Engl J Med 1991;325:373-381.

7. Lee YT, Lin RS, Sung FC, Yang CY, Chien KL, Chen WJ, Su TC, Hsu HC, Huang YC. Chin-Shan Community Cardiovascular Cohort in Taiwan-baseline data and five-year follow-up morbidity and mortality. J Clin Epidemiol 2000;53: $838-846$.

8. Wang TD, Wu CC, Chen WJ, Lee CM, Chen MF, Liau CS, Sung FC, Lee YT. Dyslipidemias have a detrimental effect on left ventricular systolic function in patients with a first acute myocardial infarction. Am J Cardiol 1998;81:531-537. 9. Friedewald WT, Levy RI, Frederickson DS. Estimation of the concentration of low-density lipoprotein cholesterol in plasma, without use of the preparative ultracentrifuge. Clin Chem 1972;18:499-502. 
10. Wang TD, Lee CM, Wu CC, Lee TM, Chen WJ, Chen MF, Liau CS, Sung FC, Lee YT. The effects of dyslipidemia on left ventricular systolic function in patients with stable angina pectoris. Atherosclerosis 1999;146:117-124.

11. Pan WH, Chiang BN. Plasma lipid profiles and epidemiology of atherosclerotic diseases in Taiwan-a unique experience. Atherosclerosis 1995;118:285295.

12. Johnson CL, Rifkind BM, Sempos CT, Carroll MD, Bachorik PS, Briefel RR, Gordon DJ, Burt VL, Brown CD, Lippel K. Declining serum total cholestero levels among US adults: the National Health and Nutrition Examination Surveys. JAMA 1993;269:3002-3008.

13. Reaven GM. Role of insulin resistance in human disease. Diabetes 1988;37 $1595-1607$.

14. Grover SA, Palmer CS, Coupal L. Serum lipid screening to identify high-risk individuals for coronary death. The results of the Lipid Research Clinics Prevalence cohort. Arch Intern Med 1994;154:679-684.

15. Corti M-C, Guralnik JM, Salive ME, Harris T, Field TS, Wallace RB, Berkman LF, Seeman TE, Glynn RJ, Hennekens CH, Havlik RJ. HDL cholestero predicts coronary heart disease mortality in older persons. JAMA 1995;274:539544.

16. The West of Scotland Coronary Prevention Study Group. Baseline risk factors and their association with outcome in the West of Scotland Coronary Prevention Study. Am J Cardiol 1997;79:756-762.

17. Pedersen TR, Olsson AG, Faergeman O, Kjekshus J, Wedel H, Berg K Wilhelmsen L, Haghfelt T, Thorgeirsson G, Pyorala K, et al. Lipoprotein changes and reduction in the incidence of major coronary heart disease events in the Scandinavian Simvastatin Survival Study (4S). Circulation 1998;97:1453-1460. 18. Gotto AM, Whitney E, Stein EA, Shapiro DR, Clearfield M, Weis S, Jou JY,
Langendorfer A, Beere PA, Watson DJ, Downs JR, de Cani JS. Relation between baseline and on-treatment lipid parameters and first acute major coronary events in the Air Force/Texas Coronary Atherosclerosis Prevention Study (AFCAPS/ TexCAPS). Circulation 2000;101:477-484

19. Grover SA, Coupal L, Hu XP. Identifying adults at increased risk of coronary disease: how well do the current cholesterol guidelines work? JAMA 1995;274: 801-806.

20. Grundy SM. Primary prevention of coronary heart disease: integrating risk assessment with intervention. Circulation 1999;100:988-998.

21. Goldbourt U, Yaari S, Medalie JH. Isolated low HDL cholesterol as a risk factor for coronary heart disease mortality. A 21-year follow-up of 8,000 men. Arterioscler Thromb Vasc Biol 1997;17:107-113.

22. Rubins HB, Robins SJ, Collins D, Fye CL, Anderson JW, Elam MB, Faas FH, Linares E, Schaefer EJ, Schectman G, Wilt TJ, Wittes J. Gemfibrozil for the secondary prevention of coronary heart disease in men with low levels of high-density lipoprotein cholesterol. N Engl J Med 1999;341:410-418.

23. Glueck CJ, Fallat RW, Millett F, Gartside P, Elston RC, Go RCP. Familial hyper-alpha-lipoproteinemia: studies in eighteen kindreds. Metabolism 1975;24: 1243-1265.

24. Sacks FM, Pfeffer MA, Moye LA, Rouleau JL, Rutherford JD, Cole TG, Brown L, Warnica JW, Arnold JM, Wun CC, Davis BR, Braunwald E. The effect of pravastatin on coronary events after myocardial infarction in patients with average cholesterol levels. N Engl J Med 1996;335:1001-1009.

25. The Long-Term Intervention With Pravastatin in Ischemic Disease (LIPID) Study Group. Prevention of cardiovascular events and death with pravastatin in patients with coronary heart disease and a broad range of initial cholesterol levels. N Engl J Med 1998;339:1349-1357. 